\title{
Суверенитет в опасности?
}

Моисеев A.A.*

Статья вносит вклад в дискуссию о природе суверенитета, его особенностях в настоящий период, в частности в условиях глобализации.

Ключевые слова: суверенитет; государство; ограничение суверенитета; глобализация.

Сразу хотел бы успокоить читателей, что с суверенитетом нашего государства все в порядке и, как показала многовековая история народа России, он в надежных руках. Речь пойдет о дискуссии, развернувшейся на страницах научных изданий, относительно природы суверенитета, его состояния и особенностей в настоящий период, в частности в условиях глобализации.

Лишний раз упоминать о важности такого качества государства, как суверенитет, полагаю, будет нецелесообразным. Сложность заключается в том, что общепризнанного определения суверенитета, закрепленного в каком-либо международно-правовом или государственно-правовом источнике, не существует. Следует признать, что суверенитет является умозрительной правовой конструкцией, которая, однако, имеет вполне ощутимые политико-правовые последствия для государств. Правильное понимание суверенитета позволяет принимать верные политические решения как внутри государства, так и вовне; напротив, недопонимание природы суверенитета ведет к таким порочным явлениям и путаным конструкциям, как «парад суверенитетов» и «суверенная демократия».

Сложность исследования суверенитета связана еще и с тем, что это явление настолько многогранно и многоаспектно, что порой, учитывая одно обстоятельство его проявления, легко упустить другие, и наоборот. Другой распространенной проблемой, с которой сталкиваешься при ознакомлении с мнениями о суверенитете, является подмена понятий или использование неточных формулировок, которые, скорее, больше путают, чем проясняют позицию автора относительно суверенитета. Встречаются и противоречащие утверждения в одной и той

\footnotetext{
* Моисеев Алексей Александрович - д.ю.н., заведующий кафедрой международного частного права Дипломатической академии МИД России, руководитель Центра международного права и международной безопасности ИАМП ДА МИД России. moiseev@ dipacademy.ru.
} 
же работе, не говоря уже о разбросе мнений разных исследователей по вопросу о суверенитете.

Самое распространенное определение суверенитета, которое обычно встречается в отечественных учебниках по правовым дисциплинам, устанавливает, что суверенитет является правовым качеством или свойством государства, символизирующим политико-правовую самостоятельность государства, его верховенство в пределах своей территории и независимость в межгосударственных отношениях от других государств ${ }^{1}$.

Определение действительно хорошее - оно лаконично, содержит указание на внутригосударственную и международные составляющие суверенитета, практично, отвечает на вопрос «Что может делать государство на своей территории и вне ее?». Существенным недостатком упомянутого определения является тот факт, что оно сформулировано с точки зрения правоспособности государства, отражает в основном его возможности и, отвечая на вопрос, что может делать государство, не отвечает на множество других вопросов - например, связанных с происхождением суверенитета, моментом его возникновения и исчезновения, распространением и т.п.

Ключевым аспектом для понимания суверенитета, полагаю, является вопрос о его делимости или неделимости, его относительной или абсолютной природе. Простой ответ на этот вопрос не проясняет сути явления. Необходим многосторонний подход к проблеме, следует ответить на ряд других вопросов, неразрывно связанных с вопросом о природе суверенитета: например, откуда появляется суверенитет, кто является его источником и носителем, когда суверенитет исчезает и в связи с чем и т.п.

В условиях значительных перемен в мире, усиления интеграции, все большей экономической взаимозависимости государств, глобализации у ряда исследователей возникает ощущение, что вместе с международными отношениями меняется и природа суверенитета. Например, «принцип суверенитета в определенном смысле размывается. Некоторые политики и исследователи предрекают закат «государственного суверенитета», хотя бы потому, что государство вынуждено «делиться» своими полномочиями с международными структурами,

${ }^{1}$ Международное право: Учебник / Под ред. А.А. Ковалева, С.В. Черниченко. М., 2008. С. 49-50. Международное право. Учебник. / Ред.колл.: А.Н. Вылегжанин, Ю.М. Колосов, Ю.Н. Малеев, Р.А. Колодкин. М., 2010. С. 165-166. 
неправительственными организациями, бизнес-сообществом и другими. Именно в этом направлении устанавливается новый мировой порядок, складывается новая модель и новое содержание суверенитета» ${ }^{2}$. Не буду останавливаться в этой статье на оценках нового мирового порядка, а также на влиянии глобализации на суверенитет, поскольку не считаю ее правовым явлением; поговорим на тему природы суверенитета.

Определенный вклад в сторону пересмотра природы суверенитета отчасти вносит вышеупомянутое определение. Не ставя под сомнение корректность и правильность указанного определения термина «суверенитет», поясню, что имеется ввиду. Как уже отмечалось, определение сформулировано с точки зрения правоспособности государства. Следуя логике определения, может создаться впечатление, что суверенитет государства и государственная власть чуть ли не идентичные понятия.

Распространенной ошибкой для понимания суверенитета является подмена понятий источника и носителя суверенитета. Например, распространенной ошибкой являются утверждения, что суверенитет есть качественная характеристика государственной власти, что «государственный суверенитет определяется как установление монополии государства на верховную власть в обществе» ${ }^{3}$, что «реальный политический суверенитет всегда принадлежит правящему классу, владеющему собственностью на орудия и средства производства... суверенитет может быть определен как установление монополии государства на верховную власть в обществе» и «характеризует собой юридическую природу государственного властвования» 4 , что «суверенитет... является сущностной характеристикой государственной власти, свидетельством ее полнокровности и могущества, вполне осязаемым качеством, реально проявляющим себя в компетенции, в наборе прав, возможностей и гарантий, обеспечивающих именно государству особый, уникальный по сравнению с другими политическими институтами статус в обществе (верховенство), равно как и в международном сообществе (независимость) ${ }^{5}$, что народ опирается на общественный и госу-

${ }^{2}$ Пастухова Н.Б. Суверенитет и федеративная организация российского государства в условиях глобализации: конституционно-правовые аспекты. Автореф. дис. д-ра юрид. наук. М., 2010. С. 39.

${ }^{3}$ Пастухова Н.Б. Государственный суверенитет: вчера и сегодня. М., 2010, С. 10.

${ }^{4}$ Пастухова Н.Б. Суверенитет и федеративная организация... С. 17-19.

${ }_{5}^{5}$ Кузьмин Э.Л. Природа государственного суверенитета // Евразийский юридический журнал. №10 (17). 2009. С. 15. 
дарственный строй, составляющие фундамент внутренней прочности и внешней независимости суверенного государства, и др. Утверждения такого рода «ставят телегу впереди лошади».

Если исходить из вышеприведенных положений и признать, что суверенитет является характеристикой государственной власти, непонятно, какое место занимает народ в известной конструкции государства: территория - власть - народ, разве что обеспечивает интересы власти государства: «людские ресурсы выступают в качестве важнейшей составляющей экономической основы суверенитета» ${ }^{6}$. Очевидно, что это не так.

Бесспорно, непосредственным реализатором возможностей государства является государственная власть. Всемирная история подтверждает, что власть в государстве меняется, исчезает и появляется, в отношении государств совершается агрессия или их оккупируют, государства переживают периоды безвластия и смуты и т.п., но суверенитет государства сохраняется - государства продолжают оставаться субъектами международного права именно благодаря народу. Нет необходимости создавать специальные условия, которые давали бы возможность утвердить власть народа как источника государственного суверенитета, поскольку именно народ является источником суверенитета. Возникновение и исчезновение суверенитета государства связано только с волеизъявлением народа - вспомним примеры ГДР - ФРГ или Чехии - Словакии.

Этой логике следует и Конституция Российской Федерации. Конституция России утверждает, что носителем и источником суверенитета в государстве является народ (п. 1 ст. 3): «Носителем суверенитета и единственным источником власти в Российской Федерации является ее многонациональный народ». В Основном законе подчеркивается, что народ является не только источником, но и носителем суверенитета именно потому, что власть в России принадлежит народу, ее представителям, то есть представителям из народа, путем их выбора из народа.

Последствием логической подмены местами народа и власти как источника суверенитета являются ошибочные рассуждения о правоспособности государства. Утверждения сводятся к тому, что власть в государстве безгранична и может по своей воле передавать свои суверенные полномочия и ограничивать суверенитет, который якобы

${ }^{6}$ Пастухова Н.Б. Суверенитет и федеративная организация... С. 20. 
представляет собой набор полномочий, является делимым, то есть относительным. Например: «суверенитет не некое абстрактно-отвлеченное понятие, а совокупность реальных, конкретных прав, полномочий иммунитетов и других возможных проявлений... в верховенстве и независимости проявляется принципиальное качество, сущность суверенитета, имеющего множество порядков градаций, выступающих его количественными характеристиками» 7 ; «решение проблемы реализации государственного суверенитета на международном уровне... требует ограничения государственного суверенитета...», «суверенитет государства не беспределен» и представляет собой «право делегировать часть властных полномочий внутри государства и за его пределами» ${ }^{8}$ и др.

Приводится даже классификация ограничения суверенитета: «Первое - добровольная уступка прав, полномочий, а тем самым и части суверенитета другому государству, союзу государств или международной организации... Второе направление связано с... решениями Совета Безопасности ООН в отношении государств... Третье направление связано с ограничениями суверенитета, грубо противоречащими международному праву (разного рода... «гуманитарные интервенции», экономические блокады, военные действия, оккупация и т.п.) и влекущими за собой в конечном счете реальную утрату суверенитета подвергшимся соответствующим акциям государством». Дальше делается вывод, что якобы «без разумного ограничения прав, а тем самым и суверенитета сегодня немыслимы идущие от жизни процессы экономической интеграции, решение стоящих перед человечеством глобальных задач, а во многом...- существование цивилизации» ${ }^{9}$. То есть, вероятно, следует понять автора так, что раньше жесткой связи суверенитета с интеграцией и глобальными проблемами не было, но потом она возникла.

Согласиться с приведенными положениями совершенно невозможно. Простые вопросы, которые возникают, если придерживаться такого подхода к суверенитету, не находят ответа и ставят в тупик: Какое количество суверенитета могут передавать государства? Одинаковое или разное количество суверенитета передают государства и как при этом соблюдается принцип суверенного равенства государств? Сколько можно передать суверенитета государству, чтобы оно не потеряло свой

\footnotetext{
${ }^{7}$ Кузьмин Э.Л. Природа государственного суверенитета. С. 14.

8 Пастухова Н.Б. Суверенитет и федеративная организация... С. 13, 19, $20,38$.

${ }^{9}$ Кузьмин Э.Л. Природа государственного суверенитета. С.15.
} 
независимый статус? Какой статус будет иметь государство, если передаст весь свой суверенитет другому государству, союзу государств или международной организации? В какой юридический момент постепенное уменьшение количественных характеристик приводит к потере качества - утрате государством своего суверенитета? и т.д.

Суверенитет не терпит к себе утилитарного отношения: из суверенитета нельзя извлекать «прок», невозможно «расплачиваться» частично своим суверенитетом, суверенитет по определению не может быть «привилегией, которую необходимо заслужить» ${ }^{10}$.

Показательным примером, характеризующим суверенитет, является развитие европейской интеграции, которая общепризнанно в мире считается наиболее продвинутой, особенно на фоне других региональных интеграционных группировок. Такая интеграция в рамках Европейского союза стала возможна, в частности, благодаря сравнительной схожести государств Европы в их политических подходах, уровне экономического и социального развития. Но даже такие близкие и похожие европейские государства принимают диаметрально противоположные решения и по вопросам, касающимся интеграции, и по вопросам вхождения в региональные группировки, например валютный союз, и по вопросам принятия т.н. «конституции» объединения, и по многим другим вопросам.

Те решения, которые принимаются большинством государств - членов ЕС, являются скорее совпадающими, а не едиными. Вопрос с европейской «конституцией» сдвинулся с места, когда из него убрали всю терминологию, намекающую на общую европейскую государственность. Ни о какой передаче суверенитета, ни о каком «добровольном самоограничении» суверенитета европейскими государствами не может быть и речи! Это касается и других суверенных государств мира.

Кажущимся противоречием абсолютной природы суверенитета является само международное право - если суверенитет абсолютен и безграничен, значит, и международное право, которое во многом является ограничивающим, якобы противоречит природе суверенитета: «поскольку основные принципы международного права происходят из международно-правовых обычаев и обязательны для всех государств... само наличие этих принципов есть косвенное согласие

10 Кузнецова Е. Суверенитет. Незыблемый или неделимый? Суверенитет государства может быть ограничен, если оно им злоупотребляет // Международная жизнь. 2004. № 7-8. C.166. 
государств на определенные ограничения их суверенитета в международных отношениях», 11 - как говорят математики, логично, но «с точностью до наоборот».

Именно международное право как система «породило» и явление суверенитета, и основные международно-правовые принципы, объективно установив допустимые рамки взаимоотношений государств, «правила игры», в пределах которых они действуют и в полной мере реализуют свой суверенитет по отношению к другим государствам. Это все равно что говорить об автомобиле без колес или о самолете без крыльев.

Правовое качество суверенитета государства, скрепленное единой волей народа, настолько устойчиво, что даже известные в истории правонарушения и преступления, совершенные государственной властью, не лишают государства международной правосубъектности. Сама по себе постановка вопроса о возможности ограничения суверенитета государства противоречит основным принципам международного права.

Возникает закономерный вопрос: а что же тогда ограничивается, что передается и лимитируется в тот момент, когда государства заключают любой международный договор, вступают в международную организацию, выполняют обязательные решения Совета Безопасности ООН и т.д., как относиться к тому, что суверенное независимое государство что-то обязано выполнять?

Для ответа на этот вопрос обратимся к общей теории права. Как известно, правосубъектность лица определяется его правоспособностью, дееспособностью и деликтоспособностью. Если кратко, правосубъектность лица указывает на наличие или отсутствие у него качества быть субъектом правоотношений, правоспособность лица указывает на способность лица иметь права и обязанности, дееспособность - на способность лица реализовывать права и обязанности, деликтоспособность - на способность лица нести ответственность за совершенные действия. В международном праве, в отличие от внутригосударственного, правоспособность и дееспособность лица в большинстве случаев совпадают. Международная правосубъектность государства является абсолютной категорией. Лицо, в нашем случае государство, либо является субъектом правоотношений в рамках международного права, либо нет - третьего не дано.

11 Пастухова Н.Б. Суверенитет и федеративная организация... С. 13. 
Подчеркнем, что суверенитет имеет прямое отношение именно к вопросам правосубъектности государства. Суверенитет указывает на качество государства быть субъектом международного права - государство либо является субъектом международно-правовых отношений, либо нет. В этом и заключается основная ценность суверенитета для государства, что его наличие делает государство субъектом международного права. Например, сравнивая с внутригосударственным правом: правовое качество физического лица иметь гражданство создает ему правовую способность вступать в многочисленные гражданско-правовые отношения.

Иначе обстоит дело с международной правоспособностью. Условно говоря, правоспособность имеет объем. Проще его увидеть у международных организаций в их уставе, где обычно указывается порядка пяти-семи функций, для реализации которых она и учреждается как производный субъект международного права. У государств таких функций безграничное количество, которое умозрительно бывает сложно осознать.

Для получения представления о функциях государства можно заглянуть, например, в Конституцию России или другого государства, где частично прописана правоспособность государства - приведен список предметов ведения Федерации (ст. 71), также там указаны предметы ведения субъектов Федерации (ст. 73), список совместных предметов ведения (ст. 72); важно, что указанные списки не являются исчерпывающими.

Правоспособность государства носит универсальный характер. Каждое суверенное государство имеет в известном смысле неограниченный объем прав, которые часто называют суверенными. Права являются суверенными, потому что являются государственными, а не потому что суверенитет государства состоит из совокупности суверенных прав. Государственные права могут быть реализованы и народом государства, и государственной властью, и ими совместно, то есть всем государством. Именно качество суверенитета является гарантией универсального объема юридических прав, который государства способны осуществлять.

В силу известного устройства государства народ государства делегирует соответствующие полномочия своим представителям, а именно государственной власти, которая в основном и занимается реализацией прав государства. Реализация правоспособности государства 
в большей степени увязывается с деятельностью государственной власти, но не исключительно. Именно государственная власть в основном представляет государство в международных делах и действует от имени государства внутри его. Именно полномочия государственной власти подразумеваются, когда речь идет о разграничении полномочий между, например, федерацией и субъектами федерации и т.д.

Важным выводом из упомянутой конструкции является то, что власть призвана выполнять волю и пожелания народа, власть зависит от народа, а не иначе. Не может «народ... опираться на общественный и государственный строй, составляющие фундамент внутренней прочности и внешней независимости суверенного государства» ${ }^{12}$; наоборот, именно «общественный и государственный строй» опирается на народ. Очевидно, что исчезновение народа ведет к исчезновению власти, а не наоборот.

Суверенитет - это качество государства, а не «сущностная характеристика государственной власти», не «целенаправленный процесс, осуществляемый высшей государственной властью...», не «установление монополии государства на верховную власть в обществе», не «качественный признак государственной власти», не «полнота законодательной, исполнительной и судебной власти на его территории» ${ }^{13}$.

Основная ошибка в понимании суверенитета заключается в его отождествлении с государственной властью. Не сложно показать, что, даже имея суверенные гарантии, власть государства во многом уязвима, зависима и ограничена. Однако исчезновение власти государства вследствие любых причин не ведет к исчезновению государства и его суверенитета. Именно государственная власть, а не суверенитет государства в определенной степени ограничивается рамками международного права, участием в международных договорах и союзах, нормами национального законодательства. Именно о «большей или меньшей «материализованности» ${ }^{14}$, «уровне, объеме, пределах» ${ }^{15}$ полномочий государственной власти, а не «суверенитета» можно говорить. Непонятно только, что подразумевается под «качественно-количественным измерением» ${ }^{16}$ суверенитета.

\footnotetext{
12 Пастухова Н.Б. Суверенитет и федеративная организация... С. 21.

13 Там же. С.17, 18, 32, 38.

${ }^{14}$ Пастухова Н.Б. Проблемы государственного суверенитета. М., 2006, С. 50.

15 Кузьмин Э.Л. - С.14.

16 Там же, C.14.
} 
Любая власть в значительной степени ограничена не только нормами международного права и внутреннего законодательства, но также политическими договоренностями, своими односторонними заявлениями и т.п., нарушение которых может привести к ослаблению власти либо к ее смене, исчезновению. В этом контексте высказывается и М. Тэтчер, говоря об ограничениях власти, «не позволяющих государству делать то, чего оно не должно делать» ${ }^{17}$.

Появление и исчезновение суверенитета связано только с волей народа. Смена или исчезновение власти совсем не означает исчезновения суверенитета. Источником суверенитета является народ! Военные столкновения, неконкурентоспособность экономики, мягкие «оранжевые» технологии, политический экстремизм, терроризм не угрожают суверенитету государства, но, бесспорно, угрожают государственной власти, ее эффективности, которая в крайнем случае может быть сменена на другую власть в государстве.

Именно потому, что государственная власть «зажата» в рамки своих обязательств и правовых норм, предвыборная риторика политических сил, претендующих на власть в государстве, в известном смысле во многом похожа и различается лишь отдельными положениями, на которых, как правило, и строится внутригосударственная политическая борьба. Но такие обязательства и правовые нормы никак не ограничивают суверенитет государства, которое благодаря суверенитету, исходящему от народа, в любой момент времени может принять любое решение.

Парадокс заключается в том, что гарантии суверенитета настолько значительны, что даже нарушение норм международного права или внутреннего законодательства государственной властью не ведет к исчезновению суверенного государства как субъекта международного права, но во многом становится поводом для падения авторитета власти как внутри государства, так и вовне или смены власти.

Именно с полномочиями государственной власти увязываем возможности государства передавать те или иные полномочия в пользу международных организаций для более эффективного решения определенных задач государства. Примечательно, что такие переданные полномочия могут быть изменены или отозваны, например, с приходом новой власти, что никак не отражается на суверенитете государства.

17 Тэтчер М. Искусство управления государством. Стратегия для меняющегося мира. М., 2003. С. 16. Цит.по: Кузьмин Э.Л. Природа государственного суверенитета. С. 15. 
Вообще передать суверенитет международной организации в любом объеме невозможно не только потому, что суверенитет - это качественная характеристика государства, а не «...право делегировать часть властных полномочий внутри государства и за его пределами» 18 , но и потому, что природа власти государства и международной организации различна.

Еще одна важная, на наш взгляд, идея. В связи с эволюцией государственного устройства, деятельностью международных организаций, развитием международных отношений и т.д. более правильным следует считать понятие суверенитета как международно-правовой категории. Действительно, суверенитет следует рассматривать как категорию международного права и как явление современных международных отношений. Если посмотреть на качество суверенитета абстрактно, то совершенно очевидно, что те последствия, которые возникают в связи с суверенитетом, касаются именно межгосударственных отношений, то есть отношений, которые возникают за границей государства. Наличие суверенитета подтверждает существование субъекта международного права и гарантирует независимость государства в международных отношениях.

Напротив, то, что в вышеупомянутом определении называется «верховенство государства на своей территории», указывает на пределы распространения государственной власти, ее юрисдикции, опять же по отношению к другим государствам. Места для суверенитета внутри суверенного государства нет. Вряд ли «суверенитет должен адаптироваться к современным потребностям с целью распределения власти внутри государства» ${ }^{19}$.

История государств также показывает, что как только вопрос касается «деления» и «перераспределения» суверенитета внутри государства - происходят трагические события. Верно, что «в результате «парада суверенитетов» Россия оказалась перед угрозой территориального распада - полного или частичного», в этом смысле не верно будет согласиться с «признанием суверенитета за субъектами федерации» с обособленным «признанием суверенитета за федеративным государством» 20 .

Нельзя пройти мимо статьи В. Зорькина «Вызовы глобализации и правовая концепция мироустройства», опубликованной в «Российской

\footnotetext{
${ }^{18}$ Пастухова Н.Б. Суверенитет и федеративная организация... С. 20.

19 Там же. С. 12.

20 Там же, С.17, 29.
} 
газете» № 204 (5283) от 10 сентября 2010 г. После ознакомления с ней больше всего удивляет то, что автор выступил не в личном, а в официальном качестве как Председатель Конституционного суда.

Не стоит давать оценки «революционным» призывам автора в пользу пересмотра Устава ООН, новой кодификации основных принципов международного права и их иерархии, а также озвученным автором новшествам в международном праве, таким как «глобальный гуманитарный дух», «международное законодательство», «трансгосударственные формальные и неформальные субъекты», «глобальные мультипликативные негативные эффекты», «глобальные нормативные институты» и т.п. Не стоит также придираться к понятию «глобальный», которое в последние годы повсеместно подменяет понятие «международный» без объяснения причин. Лучше остановиться на вопросе, непосредственно касающемся темы настоящей статьи.

Можно согласиться с необходимостью «дальнейшей разработки системы международного права в направлении ее эффективного согласования с концепцией государственного суверенитета».

Очевидно, что для эффективного согласования необходимо верно понимать, с чем мы будем согласовывать систему международного права. Возникают следующие вопросы:

a) как можно говорить о ««делегировании» суверенитетов наднациональным организациям и их юрисдикциям»?

б) что такое «добровольное объединение национальных суверенитетов на договорной основе»?

В том же ряду стоят такие нововведения, как «суверенная демократия», «ущемления государственного суверенитета» и др. Это совершенно непонятно ни с точки зрения теории международного права, ни с точки зрения практики.

Опасность, в которой находится государственный суверенитет, заключается в том, что в настоящее время он во многом утратил свой истинный смысл в понимании многих специалистов на самых разных уровнях.

\section{Библиографический список}

Зорькин В. Вызовы глобализации и правовая концепция мироустройства // Российская газета № 204(5283) от 10.09.2010 г. 
Кузнецова Е. Суверенитет. Незыблемый или неделимый? Суверенитет государства может быть ограничен, если оно им злоупотребляет // Международная жизнь. 2004. № 7-8.

Кузьмин Э.Л. Природа государственного суверенитета // Евразийский юридический журнал. № 10 (17) 2009. С. 10-19.

Международное право: Учебник. Ред. колл. А.Н. Вылегжанин, Ю.М. Колосов, Ю.Н. Малеев, Р.А. Колодкин. М., 2010.

Международное право: Учебник / Под ред. А.А. Ковалева, С.В. Черниченко. М., 2008. 825 с.

Пастухова Н.Б. Государственный суверенитет: вчера и сегодня. М., 2010. $302 \mathrm{c}$.

Пастухова Н.Б. Суверенитет и федеративная организация российского государства в условиях глобализации: конституционно-правовые аспекты. Автореферат дисс. Докт.юр.наук. - М., 2010. 46 с.

Тэтчер М. Искусство управления государством. Стратегия для меняющегося мира. - М., 2003.

\section{Sovereignty in a Danger? (Summary)}

Alexei A. Moiseev*

The article contributes to discussion over the nature of Sovereignty and current characteristics it has acquired, including the impact of globalization processes on it.

Keywords: Sovereignty; State; limits of Sovereignty; globalization.

\footnotetext{
*Alexei A. Moiseev - Doctor of Laws, head of the Chair of Private International Law of the Diplomatic Academy MFA Russia; head of the Centre of International Law and Security of the Institute of Contemporary International Studies, MFA Russia.moiseev@dipacademy.ru.
} 